\title{
Educação, formação docente e multiletramentos: articulando projetos de pesquisa-formação
}

\author{
Obdália Santana Ferraz Silva ${ }^{1}$ \\ ORCID: 0000-0002-2638-0529 \\ Úrsula Cunha Anecleto ${ }^{2}$ \\ ORCID: 0000-0002-3027-9474 \\ Sirlaine Pereira Nascimento dos Santos ${ }^{3}$ \\ ORCID: 0000-0001-9177-8261
}

\section{Resumo}

Este estudo tem como objetivo discutir a formação docente, no âmbito da Educação Básica, criando espaço para que os professores (re)pensem e (res)signifıquem suas práticas pedagógicas, tendo em vista o atual contexto sociocultural, a exigir desses profissionais que se apropriem da diversidade de linguagens, culturas e hipermídias que constituem os multiletramentos. Trata-se de um projeto guarda-chuva que articula diferentes projetos (stricto sensu), desenvolvidos em programas de Pós-Graduação de uma universidade pública, que trazem ao debate temáticas como diversidade cultural, multimodalidade, multissemiose, convergência digital, articulação entre ensino, aprendizagem e pesquisa, no âmbito da formação docente. Nesse contexto, a questão central deste estudo traduz-se da seguinte forma: como os professores têm se preparado para trabalhar os diferentes tipos de letramentos existentes, inclusive, os que envolvem as tecnologias digitais, relacionados às demandas e desafios propostos pelos (multi)letramentos? Como metodologia, optou-se pela pesquisa-formação, colaborativa, materializada por encontros formativos organizados sob a forma de sessões reflexivas. Resultados de pesquisas realizadas entre 2017 e 2018 levam à conclusão de que os projetos e políticas públicas voltados à formação de professor precisarão, diante das transformações advindas da cultura digital e dos multiletramentos, pensar a formação docente e as práticas pedagógicas, a partir de uma concepção de ensino que, efetivamente, estabeleça relação entre o conhecimento e a vida cotidiana do estudante; entre os processos de desenvolvimento humano e as possibilidades de aprendizagem oferecidas pelas agências da cultura letrada, considerando as orientações de inclusão da diversidade como princípio básico da cidadania.

\section{Palavras-chave}

Formação docente - Letramentos - Multiletramentos - Pesquisa-formação - Cultura digital.

1- Universidade do Estado da Bahia (UNEB). Salvador, Bahia, Brasil. Contato: bedaferraz@hotmail.com.

2- Universidade Estadual de Feira de Santana (UEFS). Feira de Santana, Bahia, Brasil. Contato: ursula.cunha@hotmail.com.

3- Prefeitura Municipal de Salvador, Secretaria Municipal de Educação. Salvador, Bahia, Brasil. Universidade do Estado da Bahia (PPGEDUC/ UNEB). Salvador, Bahia, Brasil. Contato: sirlainenascimento@yahoo.com.br. 


\section{Education, teacher training and multiliteracies: articulating projects of research-training}

\section{Abstract}

This study aims to discuss teacher training, within the scope of Basic Education, creating opportunities for teachers to (re)think and (res)signify their pedagogical practices, considering the current sociocultural context, to demand professionals who appropriate the diversity of languages, cultures and hypermedia that make up multiliteracies. It is a macro project that articulates different projects, developed in postgraduate programs (stricto sensu) of a public university, which raise themes such as cultural diversity, multimodality, multi-semiosis, digital convergence, articulation between teaching, learning and research, within the scope of teacher training. In this context the main question of this study focusses on the following way: How teachers have been prepared to work on the different types of existing literacies, even which involve digital technologies, related to the demands and challenges proposed by the (multi) literacies? As methodology, we opted for researchtraining, collaborative, through formative meetings based on reflective sessions. Results of researches carried out between 2017 and 2018 lead to the conclusion that public projects and policies aimed at teacher training will need, in the face of given changes by the digital culture and multiliteracies, to think about teaching training and pedagogical practices, based on a teaching conception that, effectively, stablish a relationship between knowledge and student's daily life; between human development processes and the possibilities of learning offered by the literate culture agencies, considering the guidelines for an inclusion of the diversity as a basic principle of citizenship.

\section{Keywords}

Teacher training - Literacies - Multiliteracies - Research-training - Digital culture.

\section{Pesquisa e prática pedagógica: caminhos e atalhos, do campo teórico ao campo empírico}

As Tecnologias digitais (TD) têm exercido grande influência na forma de se pensar e de se compreender o mundo; de comunicação e de interação entre os sujeitos; de entretenimento, de aprendizagem e de manifestações culturais. As mudanças promovidas pelas TD convocam-nos a discutir criticamente acerca de seus desafios e suas potencialidades para a educação, visando à ressignificação e ampliação das práticas de leitura e de escrita, fundadas nos princípios da pedagogia dos multiletramentos, que nos convida a repensar as ações pedagógicas e a formação docente no contexto da cibercultura.

Nessa perspectiva, tendo em vista as transformações e os desafios propostos pelas TD e pela pedagogia dos multiletramentos à formação docente, temos desenvolvido 
pesquisas que envolvem professores da Educação Básica, no âmbito de um grupo de pesquisa de uma universidade pública - em dois programas de Pós-Graduação -, para discutir práticas de letramentos que professores da Educação Básica têm desenvolvido em sua práxis pedagógica ${ }^{4}$, no contexto dos multiletramentos, ampliados pelas TD.

Os estudos intencionam aprofundar debates a respeito da formação docente e práticas pedagógicas, a partir de uma concepção de ensino que contemple processos de desenvolvimento humano e possibilidades de aprendizagem oferecidas pelas agências da cultura letrada, com vistas a atender às demandas das propostas educacionais, no Brasil, no que diz respeito à diversidade como princípio básico da cidadania. Dentre os projetos desenvolvidos e em desenvolvimento, trataremos aqui de pesquisas realizadas em 2017 e 2018 cujo foco é a formação docente na Educação Básica.

Os cenários de ensino e aprendizagem aos quais nos integramos, como professoras, nos inquietam e nos movem à pesquisa a partir dos seguintes questionamentos: que desafios e contribuições traz a pedagogia dos multiletramentos à formação de professores da Educação Básica, no contexto da cultura digital, visando a estabelecer uma organização pedagógica de enfrentamento da fragmentação e hierarquização dos saberes, para uma abordagem integrada e integradora das áreas do conhecimento? Como possibilitar a construção de uma prática pedagógica multiletrada que contribua para potencializar a aprendizagem dos alunos do Ensino Fundamental por meio de ações criativas/colaborativas que envolvam os diversos letramentos existentes, inclusive, os referentes às TD?

0 compromisso com a formação docente leva-nos à compreensão de que não podemos pensar mais a sala de aula senão pelos caminhos de ações formativas que contemplem as intensas demandas sociais de leitura e de escrita, considerando as transformações engendradas pelas diversidades linguística e cultural e o modo pelo qual as pessoas se comunicam, produzem saberes e constroem conhecimentos na sociedade tecnológica digital (COPE; KALANTZIS, 2000).

A formação docente tem como desafio a construção de propostas que deem aos professores a possibilidade de se multiletrar, de se formar, de construírem saberes e conhecimentos que os capacitem a desenvolver atividades pedagógicas que envolvam ações mediadas pelas TD, a partir de uma dinâmica e de uma interatividade que contribuam para ressignificar práticas de letramentos na Educação Básica. Referimo-nos a mudanças que exigem dos educadores a reflexão de práticas que se delineiam em um contexto de manifestações linguísticas pluriculturais e nos convidam a discutir, de modo mais ampliado, letramentos e multiletramentos, aqui entendidos como processos interrelacionados e não excludentes.

Este estudo representa, portanto, uma necessidade compartilhada de socializar pesquisas realizadas no âmbito da pós-graduação stricto sensu, em parceria com escolas do interior e da capital. Esperamos contribuir para a reflexão crítica e o debate a respeito da formação docente e os multiletramentos, no contexto educacional brasileiro, em que ensino e aprendizagem de leitura e escrita sejam compreendidos, para além da sala de aula física, por uma função linguístico-comunicativa para a formação de sujeitos discursivos.

4- "[...] a práxis é, na verdade, atividade teórico-prática; ou seja, tem um lado ideal, teórico, e um lado material, propriamente prático, com a particularidade de que só parcialmente, por um processo de abstração, podemos separar, isolar um do outro". (SÁNCHEZ VÁZQUEZ, 2011, p. 241). 


\section{Do texto ao contexto: reflexões teórico-metodológicas}

Como base teórica, alicerçamos este estudo na perspectiva da linguagem como mediadora entre sujeito e história, em que a escrita é compreendida como processo interativo, social, histórico e dialógico (BAKHTIN, 2004). No campo da formação de professor, ressaltamos a importância dos saberes docentes para o desenvolvimento profissional dos professores (PIMENTA; GHEDIN, 2002). Trataremos dos significados e concepções de letramento como estado ou condição daquele que se apropria da escrita (SOARES, 2004; KLEIMAN, 2005); letramento relacionado às transformações ocorridas na sociedade centrada na escrita com suas múltiplas funcionalidades, com demandas que os sujeitos precisam atender (TFOUNI, 2010); letramento como prática social, variando, portanto, conforme os contextos (STREET, 2012, 2014). Discutiremos a concepção de multiletramentos correlacionada à diversidade linguística e cultural (NLG, 2000; COPE; KALANTZIS, 2000; ROJO, 2009, 2012, 2013; ROJO; BARBOSA, 2015); letramento digital como meio para a individuação e, ao mesmo tempo, espaço para representações coletivas (IBIAPIANA; RIBEIR0; FERREIRA, 2007), que visa à construção da competência comunicativa ${ }^{5}$ dos alunos.

\section{Práticas de letramentos e multiletramentos na formação de professores: meio para construção da competência comunicativa}

As práticas pedagógicas de leitura e de escrita realizadas em sala de aula farão mais sentido aos alunos se forem fundamentadas no desenvolvimento da competência comunicativa, na formação reflexiva e no processo de ensino e aprendizagem colaborativo, visando à promoção do pensamento crítico, à intensificação da interação mútua entre alunos e professores. Sabemos que, em uma sociedade letrada, em que a escrita se tornou um meio de interação entre os sujeitos e a leitura uma forma de entendimento do mundo, essas práticas (tanto em mídias impressas quanto em digitais) devem garantir o desenvolvimento sociocultural e cognitivo do sujeito aprendiz (BAZERMAN, 2007), de modo a contribuir para a construção da competência comunicativa (HYMES, 2009) desse sujeito.

Letramento, nesse contexto, representa um processo de aprendizagem social e histórica da leitura e da escrita, surgindo "como uma forma de explicar o impacto da escrita em todas as esferas de atividades e não somente nas atividades escolares" (KLEIMAN, 2005, p. 6). É nesse sentido que ampliamos as possiblidades das investigações do grupo de pesquisa no qual atuamos, levando em conta que os estudos sobre práticas de letramento pressupõem um conjunto diversificado de práticas sociais situadas que envolvem um sistema de signos, como a escrita ou outras modalidades, para produzir sentidos (ROJO, 2009).

As pesquisas que realizamos nos autorizam a interpretar que práticas de letramentos em diversas esferas, tanto escolares como extraescolares, têm objetivos sociais relevantes

5- A competência comunicativa engloba elementos da língua (competência linguística) e do texto (competência textual), constituindo-se, assim, um dos enfoques de ensino de Língua Portuguesa na Educação Básica para a ampliação dos letramentos dos alunos. 
para os participantes da situação e apresentam consequências sociais e culturais que são coletivas. Ser letrado, então:

[...] é participar de um conjunto de práticas sociais nas quais significados e sentidos de certos conteúdos codificados culturalmente (tradicionalmente, mas não exclusivamente, textos escritos) são gerados, disputados, negociados e transformados. (BUZATO, 2010, p. 53).

Esses são novos saberes proporcionados pela cibercultura que exigem o aprendizado de outros letramentos, além do escolar, pois as ações que envolvem leitura e escrita, hoje, demandam o uso de diferentes linguagens, novos estilos de raciocínio e conhecimento, dada a multiplicidade de significados atribuídos ao letramento.

Considerando que "[...] os produtores de textos fazem um uso cada vez maior e mais deliberado de uma gama de modos de representação e comunicação que coexistem dentro de um texto dado" (KRESS; LEITE-GARCIA; VAN LEUWEEN, 2000, p. 374, tradução nossa) ${ }^{6}$, a unidade escolar, como agência de letramentos e de multirreferencialidade, terá o papel de implementar um conjunto de práticas de leitura e de escrita - valorizadas ou não, locais ou globais - que abranjam contextos sociais diversos, contribuindo, dessa forma, para a ampliação da competência comunicativa de seus alunos. Portanto, lembra-nos Ferreira (2018, p. 43) que:

[...] o processo de leitura, em uma sociedade multimídia, não deve ficar restrito aos elementos verbais, ou seja, os elementos visuais (imagens, sons, movimentos, cores, diagramação, formatos e destaques) devem ser considerados como elementos constitutivos que contribuirão, de forma significativa, para formar o ato comunicativo.

A competência comunicativa pressupõe uma ampliação dos conhecimentos linguísticos em relação à leitura e à escrita e leva em conta a variação da língua e normas sociais e culturais que fazem parte dos contextos comunicativos:

[...] a aquisição desse tipo de competência é obviamente alimentada pela experiência social, necessidades e motivos, e questões na ação que é em si mesma renovada fonte de motivos, necessidades, experiências. (HYMES, 2009, p. 86).

Por sua diversidade de formas textuais, a competência comunicativa é uma espécie de "etnografia de formas simbólicas" (HYMES, 2009, p. 94): representação da variedade de gêneros, linguagens e modos textuais que se inter-relacionam com necessidades comunicativas de uma sociedade. Nas pesquisas que realizamos, compreendemos a competência comunicativa como um sistema de conhecimento linguístico e habilidades comunicativas, exigidas nos processos de produção textual, em diversas práticas de letramentos.

$\mathbf{6}$ - "[...] los productores de texto hacen un uso cada vez más mayor y más deliberado de una gama de modos de representación y comunicación que coexisten dentro de un texto dado". 
Centramo-nos em investigar como ocorrem essas ações letradas no espaço escolar pela perspectiva do letramento ideológico (STREET, 2014): práticas de escrita associadas ao contexto social, cultural e estrutura de poder da sociedade. Então, entendemos o sujeito como ator social, que deseja dar um sentido às suas experiências de vida, valorizar sua criatividade e singularidade cultural, por meio da diversidade de linguagem, semiose e mídias, isto é, dos multiletramentos.

Ao caracterizarmos os letramentos como múltiplos, estamos referindo-nos às diferentes culturas, em oposição a um letramento e a uma cultura únicos; e ao tratarmos de multiletramentos, falamos sobre as diversas formas de letramento que se associam a canais ou modos de comunicação em que se realizam as práticas de leitura e de escrita - letramento do computador, letramento visual. Street (2012) explica-nos que o The New London Group $(N L G)^{7}$, ao apresentar a noção de multiletramentos, "[...] está interessado especialmente em canais e modos de comunicação que podem ser denominados de ‘letramento”'. (STREET, 2012, p. 73, grifo do autor)

A concepção de multiletramentos que embasa nossas pesquisas parte da ideia apresentada pelo NLG (2000) e se amplia para abranger aspectos essenciais ao entendimento das ordens discursivas na atualidade: a multiplicidade de linguagem, semioses e mídias que caracterizam os textos que circulam na contemporaneidade, e a multiplicidade cultural dos centros urbanos (ROJO, 2012), conforme organizamos a seguir.

Figura 1 - Conceitos que constituem os multiletramentos

\begin{tabular}{|c|c|c|c|c|c|c|c|}
\hline & & & MULTILET & IMENTOS & & & \\
\hline $\begin{array}{l}\text { Letramento } \\
\text { hipermidiático }\end{array}$ & $\begin{array}{l}\text { Letramento } \\
\text { digital }\end{array}$ & $\begin{array}{l}\text { Letramento } \\
\text { crítico }\end{array}$ & Multimodalidade & Multiculturalidade & Hipertexto & Cidadania & Inclusão \\
\hline
\end{tabular}

Os multiletramentos envolvem os letramentos hipermidiáticos, os quais se tecem da combinação entre as múltiplas culturas e as diferentes modalidades semióticas que se ampliam com as TD e se multiplicam em nós hipertextuais que relacionam significados e fazeres, os quais precisam ser ressignificados por professores e alunos, a partir de uma leitura crítica. São práticas semióticas multimodais e multiculturais, das quais, ao nos apropriamos, experimentamos novos relacionamentos, novas formas de humanidade, outras práticas de comunicação e outras redes sociais. Essas práticas desafiam-nos a pensar novos paradigmas para o ensino e para a aprendizagem.

A multiplicidade de linguagens e os recursos multimodais e multissemióticos que têm circulado em redes ecossociais cada vez mais amplas desafiam o professor da Educação Básica a se multiletrar, a partir de uma formação pessoal e profissional responsiva que o possibilite transitar pelas práticas interativas discursivo-textuais e hipertextuais demandadas pelo contexto sociocultural em que vive. De acordo com Street (2014), os

7- Grupo de Nova Londres (GNL). 
letramentos são ideológicos, variam no tempo e no espaço, pois estão interligados ao contexto social, às práticas culturais e às relações de poder existentes.

Múltiplos letramentos são produzidos com a evolução das TD, a partir das quais emergem modelos culturais, representantes das próprias vivências dos indivíduos em seu meio, tendo em vista os seus sistemas de comunicação, de produção e as relações sociais em rede. Assim, na simbiose homem e tecnologia digital, surge a cibercultura que é a infraestrutura tecnológica, mas também os seres humanos que, conectados, navegam no universo oceânico da informação; um conjunto de técnicas e, igualmente, de práticas, atitudes, comportamentos, valores, pensamentos que são desenvolvidos, coletivamente, no ciberespaço (LÉVY, 1999).

Na cibercultura, os letramentos avançam para além do impresso e tornam-se partes integrantes da cultura digital; constituem-se como práticas sociais, como processos contemporâneos que formatam textos em gêneros discursivos, entretecidos por várias semioses, as quais integram os novos letramentos ${ }^{8}$. É desse modo que se configuram os multiletramentos que dizem respeito à multiplicidade - cultural e semiótica - de práticas letradas da sociedade em rede.

Os princípios dos multiletramentos, baseados em um ensino contextualizado e interdisciplinar, pressupõem um trabalho pedagógico que considere as diversas manifestações culturais presentes em sala de aula, a partir da elaboração de atividades que envolvam processos de letramentos multissemióticos e multimodais ${ }^{9}$, pautados em mudanças de perspectivas teórica e prática.

Cope e Kalantzis (2000, p.18, tradução nossa) sinalizam que a proposta de uma pedagogia dos multiletramentos é desenvolver "[...] uma epistemologia do pluralismo que proporcione acesso sem que as pessoas precisem apagar ou deixar para trás suas diferentes subjetividades"10. Isso significa levar em consideração as múltiplas e diversas realidades cotidianas dos alunos e as trajetórias individuais de aprendizado. Para tanto, o professor poderá construir uma base norteadora de sua práxis que envolva a concepção de linguagem relacionada ao seu uso sociocultural, à diversidade e à multimodalidade textual, possibilitadas pela utilização das TD, direcionados à construção coletiva e colaborativa de conhecimento.

A cultura digital, no que tange, principalmente, às práticas sociais de leitura e de escrita multiletradas, desafia o professor ao trabalho com a linguagem, a partir de seus usos sociais, envolvendo a convergência de diversos gêneros multimodais e multissemióticos, produzidos, colaborativamente, em rede: "0 desafio fica colocado pelas nossas práticas escolares de leitura/escrita que já eram restritas e insuficientes mesmo para a era do impresso" (ROJO, 2012, P. 22). Professores são desafiados a entender e a manipular as

\footnotetext{
8- De acordo com Street (2014), os novos estudos do letramento entendem a escrita não apenas do ponto de vista (psico)linguístico, mas também histórico, antropológico e cultural, levando em consideração as relações de poder. Essa é uma compreensão do letramento como prática social.

9- Os textos multissemióticos ou multimodais são constitutivos de muitas linguagens (modos ou semioses) e "[...] exigem capacidades e práticas de compreensão e produção de cada uma delas (multiletramentos) para fazer significar" (ROJO, 2013, p.19). Os textos contemporâneos, seja em veículos impressos, seja nas mídias analógicas e digitais, são compostos de elementos como: "Língua oral e escrita (modalidade verbal), linguagem corporal (gestualidades, danças, performances, vestimentas - modalidade gestual), áudio (música e outros sons não verbais - modalidade sonora) e imagens estáticas e em movimento (fotos, ilustrações, grafismos, vídeos, animações - modalidades visuais)". (ROJO; BARBOSA, 2015, p. 108). 10- "[...] an epistemology of pluralism that provides access without people having to erase or leave behind different subjectivities".
} 
formas de representação multimodal, as imagens articuladas à palavra escrita, o que demanda uma preparação específica e diferenciada (NLG, 2000).

Considerando a complexidade da práxis pedagógica multiletrada, para efetivá-la, o professor precisará enfrentar o desafio de desenvolver práticas de letramentos situados com os alunos da Educação Básica, tendo em vista as suas experiências com linguagens multimodais, multissemióticas, hipertextuais, vivenciadas por eles fora do contexto escolar. Tais práticas precisam estabelecer relações entre cultura digital e cultura escolar, em que a escola possa assumir o papel de protagonista, criando possibilidades pedagógicas que contemplem políticas de incorporação das tecnologias em suas práticas formativas.

\section{Pesquisa colaborativa: uma opção epistemológica para produção de conhecimento e reelaboração da prática}

A escolha da metodologia para análise dos dados toma como princípio o estudo interpretativo, entendido como "[...] uma questão de foco substantivo e intenção, e não uma questão de procedimentos para a recolha de dados"11 (ERICKSON, 1986, p. 120, tradução nossa). Realizaram-se análises de dados nas dimensões textual (conteúdo do texto), temática (percepção e argumentação do tema) e interpretativa (identificação dos pressupostos, explícitos e implícitos nos discursos dos participantes), para uma posterior discussão e reflexão de questões levantadas pelos participantes da pesquisa (SEVERINO, 2002).

Esse processo formativo colaborativo implicou uma relação de reconhecimento dos pressupostos teóricos que permeiam a práxis pedagógica dos partícipes. A mediação dos pesquisadores, nesse processo, foi importante para proporcionar momentos de reflexão da prática, fazendo emergir conceitos implícitos e apresentando outros conhecimentos de maneira a provocar a ressignificação e/ou intervenção da realidade. Promovemos, desse modo, encontros para diálogo e reflexão acerca da prática pedagógica cotidiana, visando a uma produção de conhecimento significativa, que abarcasse o mundo de vivências docentes, tecido por intercâmbios simbólicos, interesses sociais e correspondências afetivas (GÓMEZ, 1998).

A opção pela pesquisa-formação surge como um contraponto das pesquisas que reduzem os professores a apenas objetos de estudo e como proposta de pesquisa que desafia o pesquisador a investigar com os sujeitos. Nesse sentido, propusemos encontros formativos, visando a ações colaborativas que geraram processos de intervenção no contexto escolar, os quais foram movidos pela necessidade de transformação da prática pedagógica (ANDRÉ, 2002). Tais encontros, configurados como sessões reflexivas, possibilitaram a participação ativa dos professores nos processos de investigação de situações-problema.

As sessões foram norteadas por provocações/questionamentos que direcionam as discussões a respeito das contribuições, desafios e implicações teórico-metodológicas dos multiletramentos na formação e práxis do professor da Educação Básica, contribuindo para

11- "[...] is a matter of substantive focus and intent, rather than of procedure in data collection". 
a problematização das responsabilidades e competências deles exigidas, na sociedade digital. 0 princípio da reflexividade que permeia as pesquisas desenvolvidas toma como orientação os momentos denominados por Ibiapina (2008) de "ações reflexivas", a saber: descrição (Como tem sido a minha prática?); informação (Qual o sentido e qual a base histórica das práticas de ensino?); confronto (Qual a função das escolhas feitas na construção da cidadania?); reconstrução (0 que tenho de fazer para mudar a minha prática?).

Nessa perspectiva, as investigações realizadas transitam por métodos que visam à participação dos sujeitos como parceiros e coautores. Orientados pelos princípios da pesquisa colaborativa, criamos espaço para que os professores pudessem discutir, refletir, intervir e produzir questionamentos a partir da sua práxis. A pesquisa colaborativa tem potencial para:

[...] dar conta não somente da compreensão da realidade macrossocial, mas, sobretudo, em dar poder aos professores para que eles possam compreender, analisar e produzir conhecimentos que mudem essa realidade, desvelando as ideologias existentes nas relações mantidas no contexto escolar. (IBIAPINA; RIBEIRO; FERREIRA, 2007, p. 31).

Apropriamo-nos da pesquisa colaborativa como perspectiva teórico-metodológica que nos possibilitou criar sessões reflexivas que se constituíram em momentos de formação contínua, nos quais foram consolidados e partilhados, coletivamente, conhecimentos. Tomamos como focos de discussão a pedagogia dos multiletramentos, a prática docente e a formação de professores, visando a contribuir, a partir de conhecimentos teóricos já construídos, para uma reconfiguração da práxis na Educação Básica.

Partindo desse princípio, as pesquisas de caráter formativo, concluídas até 2018, têm considerado a complexidade do fazer pedagógico com a qual o professor constantemente se defronta para, a partir daí, pensar, colaborativamente, em reconfiguração da prática pedagógica, considerando os problemas que a condicionam.

\section{Do processo de investigação às vivências no campo educacional: alguns resultados}

Os resultados aqui apresentados dizem respeito às pesquisas desenvolvidas e concluídas entre 2017 e 2018, envolvendo formação docente para as práticas de letramento, tanto nos gêneros impressos quanto nos digitais. Neste estudo, destacaremos os projetos de pesquisa e extensão que envolveram escolas do interior e da capital: Tecnologias, (multi)letramentos e formação de professores e Formação continuada em multiletramentos: ressignificando as práticas pedagógicas com a inserção das tecnologias digitais móveis.

\section{A pesquisa e a extensão como ações formativas com docentes que atuam em escolas do interior}

A pesquisa intitulada Tecnologias, (multi)letramentos e formação de professores ${ }^{12}$, que gerou o projeto de extensão com o mesmo título, foi apoiada por uma Pró-reitoria

12- A pesquisa Tecnologias, (multi)letramentos e formação de professores constituiu uma das ações realizadas nos programas de pósgraduação em que atuamos. Em sua primeira etapa, iniciada em 2017, atingiu quatro municípios do interior baiano. A segunda etapa, o Projeto de 
de extensão e por um núcleo de pesquisa da instituição proponente. Teve como objetivo elaborar diagnóstico sobre o uso das tecnologias digitais nas salas de aula, por professores da Educação Básica. No período de março a julho de 2017, em que foi desenvolvida, realizamos entrevistas de caráter semiestruturado com 47 professores $^{13}$ dos anos iniciais do Ensino Fundamental da rede municipal e 15 graduandos do $8^{\circ}$ semestre do curso de Letras com habilitação em Língua Portuguesa, de uma universidade pública.

0 projeto de extensão, realizado no período de abril a dezembro de 2018 , teve como objetivo discutir estratégias de organização dos tempos e espaços educativos, levandose em conta a existência de redes tecnológicas que contribuam para a construção/ reconstrução de conhecimentos, a partir de ambientes físicos e digitais. Nesse período, discutimos algumas temáticas sugeridas pelos docentes, quando da reflexão sobre suas próprias práticas docentes: cultura digital e educação escolar; educação escolar e tecnologias digitais; mediação pedagógica e uso das TD; multiletramentos e letramentos digitais críticos.

Tomando como metodologia a pesquisa colaborativa, organizamos atividades sob a forma de minicursos e rodas de conversa. Os minicursos, considerados como espaço-tempo formativo para estudo teórico, priorizaram a problematização das práticas pedagógicas que foram realizadas pelos professores, com os usos das TD. As rodas de conversa possibilitaram aos cursistas refletir, colaborativamente, acerca das ações cotidianas e escolares, das TD e suas implicações para a formação do professor.

Com essa investigação, intentamos conhecer as TD presentes na escola, na vida pessoal do professor, mesmo que, muitas vezes, não façam parte da sua prática pedagógica:

Utilizo computadores, celulares, televisões com diversos recursos. Essas tecnologias... é, é me ajudam muito, como por exemplo na facilidade de comunicação com as pessoas, a facilidade de resolução de problemas corriqueiros como administrar as finanças via internet, facilita no acesso a textos, livros e demais materiais de estudo, incluindo minha formação já que tenho buscado cursos de especialização a distância, trazendo praticidade na minha rotina. (Professora Nany). ${ }^{14}$

Nossas pesquisas têm contribuído, ainda, para a compreensão de como professores e futuros professores das escolas pesquisadas concebem e utilizam as TD em sua sala de aula; bem como para identificar concepções teórico-metodológicas evidenciadas pelos professores nessa utilização:

[...] a gente utiliza as diversas linguagens em sala de aula, a gente está potencializando a aprendizagem, pois ele permite que a criança tenha a oportunidade de vivenciar, de experimentar né... possibilidades inúmeras de aprendizagens, em respeito a essa singularidade (pausa) que cada

Extensão com docentes da Educação Básica, foi realizada em 2018. Na terceira etapa, realizada em 2019, pretende-se verificar, in loco, resultados do processo formativo.

13 - Termos de cessão de direitos autorais foram assinados por todos os professores participantes.

14- Os nomes dos participantes das pesquisas são fictícios, para preservar a identidade dos professores participantes. São pseudônimos escolhidos por eles mesmos. 
indivíduo tem de aprender (pausa). E acho que a gente tem caminhado de uma forma... é... que tem trazido isso com bem mais ênfase, né pra nossa sala de aula. Seja através da música, seja através dos jogos, seja através é... dos vídeos, né... seja através do próprio computador, do celular, né [...]. (Professora Ágata).

Nessa primeira etapa de pesquisa, verificamos que professores e futuros professores utilizam as TD em diversas ações em sua vida cotidiana, inclusive para atender situações pessoais de aprendizagem. Entre os meios mais utilizados por esses sujeitos estão redes sociais, aplicativos de mensagens e gênero textual e-mail. Dos entrevistados, 60\% informaram que, em 2017, utilizaram alguma TD na sala de aula com os alunos. Entretanto, apesar de as TD se constituírem em meios que contribuem para a realização de ações discursivas cotidianas desses sujeitos, seus discursos mostraram-nos que, muitas vezes, essas tecnologias e suas potencialidades textuais ainda não são elementos integrantes de suas aulas.

Em situações pontuais, as tecnologias fazem parte da sala de aula, pois professores e alunos usam artefatos digitais; porém, geralmente, constituem-se mais como instrumento para, por exemplo, exibição de slides, promoção de pesquisa extra-classe, transmissão de informação, sem que, contudo, essas mídias, seus textos e intencionalidades sejam devidamente problematizados:

Utilizo, pelo menos uma vez por semana, as tecnologias móveis (aparelho celular) em sala de aula, com o objetivo de realizar pesquisas específicas sobre conteúdos da disciplina. (Professora Ana).

Quando os alunos precisam apresentar atividades em grupo, a exemplo de seminários, utilizo notebook e datashow como forma de exibir as apresentações. (Professora Bete).

Costumo, diante da carência da unidade escolar, ler no próprio livro para as crianças, mostrando as ilustrações. (Professora Mel).

0 trabalho com textos da esfera digital representa um desafio para docentes na atualidade, ainda limitados ao uso do impresso. Isso não quer dizer que eles não utilizam tecnologias digitais em suas aulas, mas que ainda não se apoderaram com criticidade da multiplicidade de linguagem e de signos, do potencial pedagógico que os textos pertencentes ao gênero digital apresentam, a fim de que possam os abordar ou os explorar satisfatoriamente em sua prática pedagógica, visando ao ensino e à aprendizagem de leitura e de escrita dinâmicas e interativas.

Entendemos que as TD podem, de fato, ser utilizadas como agente integrador das aulas, com a finalidade de ampliar os letramentos dos alunos. Os dados construídos a partir das entrevistas levam-nos a interpretar que professores da Educação Básica compreendem a complexidade de uma prática que envolva os multiletramentos. Entretanto, a inclusão das textualidades digitais representa um desafio para seu fazer pedagógico: 
[...] propor uma prática de multiletramentos requer planejamento, conhecimento de várias possibilidades, metodologias que uma situação didática requer, além de pesquisas também. Requer também, criticidade por parte do professor para que possa filtrar as informações necessárias. (Professora Mel).

Os professores compreendem também que os modelos de letramento mudam, porque são situados e históricos e precisam acompanhar as transformações de cada contexto tecnológico, social, político, econômico, cultural em uma sociedade:

Com certeza, trabalhar na perspectiva dos multiletramentos potencializa a aquisição da leitura e da escrita. Pois, na atualidade, se não buscarmos acompanhar as tecnologias, certamente, estaremos nos colocando, num "futuro próximo", às margens da sociedade. 0 mundo gira em torno dos avanços tecnológicos. (Professora Nany, grifo da professora).

Essa reflexão ocorreu em um dos momentos formativos, promovidos pelo projeto de extensão, quando finalizamos as atividades da primeira etapa do projeto de extensão, tecendo considerações a respeito das transformações sociais e tecnológicas que ocorrem no contexto atual, as quais se ampliam e se diversificam, tanto no que diz respeito ao compartilhamento de informações e conhecimento como nos modos de produzi-los.

\section{A pesquisa e a extensão como ações formativas com docentes que atuam em escolas da capital}

0 projeto de pesquisa e extensão semipresencial, intitulado Formação continuada em multiletramentos: ressignificando as práticas pedagógicas com a inserção das tecnologias digitais móveis, fınanciado pela Pró-reitoria de extensão da instituição de ensino superior proponente, foi aplicado por uma mestra e uma mestranda, sob a responsabilidade de uma professora orientadora. Teve como objetivo promover a formação continuada de professores de escolas municipais, visando à elaboração colaborativa e ao desenvolvimento de projetos e atividades que potencializem ações pedagógicas e fortaleçam o processo de ensino e de aprendizagem nos anos finais do Ensino Fundamental. Participaram do projeto 57 professores de escola municipais da capital; dentre eles, 54 também assumiam a função de coordenadores nas escolas onde atuavam.

Ao tomar por base a análise dos dados gerados nas rodas de conversa e nas entrevistas semiestruturadas, construímos, de forma colaborativa, o projeto de Extensão, visando a atender às demandas detectadas a partir das situações apresentadas pelos docentes. Esse projeto constitui uma das ações no âmbito dos Programas de pós-graduação em que atuamos. Foi organizado em dois módulos: 44 horas presenciais e 56 horas à distância, assim distribuídas: $36 \mathrm{~h}$ de atividades no Moodle e $20 \mathrm{~h}$ de aplicação de atividades em sala de aula.

Nos encontros presenciais problematizamos, colaborativamente, o uso das tecnologias digitais móveis na sala de aula, conhecemos as práticas pedagógicas multiletradas já realizadas pelos professores e incentivamos a construção de novos fazeres dentro da escola, considerando a existência de novas mídias e hipermídias para a construção de conhecimento e para a promoção de diálogos entre os sujeitos participantes do projeto. 
As ações desenvolvidas nesse projeto de extensão tiveram como eixo norteador as temáticas apresentadas pelos professores no primeiro encontro: cultura digital e educação escolar; mediação pedagógica e construção de conhecimentos em rede; multiletramentos e práticas de leitura e de escrita em diversas mídias e hipermídias; modalidades textuais. Para a discussão desses temas, lançamos mão das rodas de conversa, nos encontros presencias, a fim de que os participantes pudessem refletir, colaborativamente, acerca dos fatos do cotidiano, da sua cultura, da sua comunidade interligados ao fazer pedagógico.

Nesse processo formativo, os professores expuseram suas necessidades, que diziam respeito ao redimensionamento de suas ações pedagógicas para acolher novos gêneros, novas textualidades, novos comportamentos sociais referentes às práticas de uso das linguagens oral e escrita, levando-se em conta outros modelos de intepretação dos fenômenos comunicativos e suas consequências sociais; ou seja, outros letramentos e multiletramentos. Esse diálogo inicial levou à discussão da pedagogia dos multiletramentos como possibilidades de desenvolvimento de práticas pedagógicas que envolvam as linguagens multimodais e multissemióticas, bem como à reflexão de que a escola não poderá ficar alheia a esse movimento, pois somos integrantes de uma sociedade cujas relações se dão em rede e pelo hibridismo das conexões, digitais ou não. Nesses momentos reflexivos, os professores revelaram a importância das discussões temáticas para ampliação de saberes e conhecimentos:

[...] este curso ampliou o meu conceito e sobretudo me mostrou diversas formas novas de trabalhar com outras mídias, principalmente as mídias digitais e gamificação. (Profa. Marize).

A pedagogia do multiletramento tira o professor do modelo antigo, que demorou muito para se renovar, e apresenta uma riqueza de possibilidades mais próximas da criança e do jovem de hoje. A inclusão de novas mídias na sala de aula aproxima o estudante do conhecimento, pois fala também a sua linguagem mais usada, a linguagem digital. 0 multiletramento em todas as escolas é também uma forma de inclusão social pois possibilita ao estudante de baixa renda o acesso aos mesmos recursos e linguagens que estão sendo usadas nas escolas de classe média. (Profa. Rosa).

Nos excertos, os professores reconhecem a importância dos multiletramentos em tempos de comunicação digital e a necessidade de se desenvolver novos projetos, nos anos fınais do ensino fundamental, que lhes propiciem realizar práticas alicerçadas na pedagogia dos multiletramentos, a partir do uso crítico e reflexivo das multimídias e hipermídias, visando a contribuir para a construção da competência linguística e, possivelmente, para a inclusão social dos alunos, como assinala Rosa.

Para além de se pensar atividades envolvendo a diversidade de linguagens, os multiletramentos, na visão dessa professora, possibilitam aos sujeitos dialogar com textos multimodais e multissemióticos - das esferas impressa e digital - que fazem parte de suas culturas locais, ampliando as possibilidades de produção de conhecimento, do local ao global. Mas, como observa o professor Jânio, são mudanças que desafiam a escola a desenvolver um trabalho colaborativo, que envolva as comunidades local e escolar em projetos a partir dos quais os alunos, conforme esclarece a professora Isa, possam 
desenvolver sua competência comunicativa, ao usarem as tecnologias digitais para explorar potencialidades, construir, transformar, reconstruir, exercer a cidadania:

Antes do curso, nunca tinha ouvido falar de multiletramentos. Acredito que seja uma perspectiva pedagógica possivel, entretanto, teríamos que rever nossas práticas, geralmente conservadoras, o que torna a mudança um grande desafio para todos na escola. (Prof. Jânio).

É pensar na escola que forme para o trabalho, para a cidadania, para a vida pessoal levando em conta todo o conhecimento que essa criança possui. Onde professor e aluno agem colaborativamente, onde todos aprendem e ensinam. Professor e aluno, aluno e aluno, família, aluno e escola. Claro que para isso é necessário que queiram realmente essa transformação e educadores que utilizem na sua vida acadêmica o que já usam na sua vida privada. Que saiam do senso comum e explorem os diferentes saberes e inteligências que nossos alunos possuem. (Profa. Isa).

Retomando a fala da professora Rosa, podemos interpretar que ela corresponde à relevância de se pensar uma pedagogia de projetos que não se limite, apenas, ao desenvolvimento de conteúdos disciplinares ("modelo antigo"), mas que propicie ao professor realizar experiências de multiletramentos na Educação Básica; isto é, organizar atividades didáticas que oportunizem aos alunos o contato com as múltiplas linguagens e com a diversidade cultural, características da sociedade atual. Uma proposta de trabalho nesse sentido poderá se concretizar a partir de aparatos dos quais os alunos já dispõem - celular e tablet -, mas não poderá se limitar ao uso desses recursos, como observam as professoras Ana e Luz:

Aprendi também, neste curso, que o investimento em recursos didáticos que favoreçam o multiletramento, principalmente em mídias digitais, é urgente e muito necessário, mas nós podemos iniciar nesta cultura de multiletramento, mesmo com o pouco recurso que temos, como por exemplo um celular ou um tablet. 0 que não podemos mais é continuar insistindo com uma Pedagogia do século XIX para um estudante do século XXI. (Profa. Ana).

[...] no curso pude aprender que essas "tecnologias" não se resumem simplesmente a aparatos tecnológicos. A Pedagogia dos Multiletramentos é possível, na minha opinião, quando o professor é um pesquisador. Não basta falar que é “multiletrado”. É preciso ser e viver!! (Profa. Luz, grifos das autoras).

Para promover seu engajamento a esse novo contexto digital, a fim de transformar sua sala de aula em espaço de produção de conhecimento e de interação, é preciso que haja, por parte do professor, a pesquisa contínua, como enfatiza a professora Luz: "A Pedagogia dos Multiletramentos é possível [...] quando o professor é um pesquisador”.

Ademais, o professor não poderá se furtar de lançar mão de atividades que priorizem o desenvolvimento do senso crítico dos sujeitos, articulado às diversas linguagens com que são tecidas as relações sociais. Como alerta a professora Ana, "não podemos 
mais é continuar insistindo com uma Pedagogia do século XIX para um estudante do século XXI". O professor precisará ser um mediador, de modo a contribuir para que as informações veiculadas nas diversas mídias sejam transformadas em conhecimento, a partir do movimento de ação-interação-ação com os alunos.

Realizar práticas multiletradas é muito mais do que ser usuário/consumidor dos artefatos tecnológicos. Perpassa pela capacidade de produção, construção e remixagem de conhecimentos nos ambientes digitais; demanda um aprofundamento crítico das linguagens multissemióticas, na busca de se produzir sentidos para uma aprendizagem mais significativa que poderá culminar na transformação das práticas pedagógicas, na comunidade escolar, de modo que reverberem dentro e fora dela.

Se o professor se apropria das tecnologias para suas atividades cotidianas, não deverá ser diferente na sala de aula, em que, como mediador, poderá propiciar o desenvolvimento de produções colaborativas, instigando o espírito investigativo de seus alunos, incentivando-os a criar percursos criativos e dinâmicos de aprendizagem, a partir de projetos de leitura e de escrita: "Para tal, é preciso que a escola se interesse por e admita as locais de alunos e professores" (ROJO, 2009, p. 115).

É possivel interpretar, pelas reflexões nos encontros formativos, que os professores compreendem a importância da integração das TD em sala de aula, para a criação de novas possibilidades de expressão e de comunicação; que a escola não poderá ignorar a evolução tecnológica contemporânea: "A escola não pode desconhecer esta realidade que se aproxima com o novo milênio e, muito menos, caminhar em sentido oposto ao que ocorre do lado de fora dos seus muros” (PRETTO, 2013, p. 122).

As reflexões e discussões teórico-práticas das temáticas, realizadas nos encontros formativos presenciais, sempre eram aprofundadas e ampliadas no ambiente virtual Moodle, visando ao desenvolvimento de atividades, em sala de aula, que proporcionassem aos alunos experiências interativas e dinâmicas, com o uso planejado de dispositivos móveis:

[...] Observar o brilho nos olhos dos alunos quando eles se viram protagonistas nas "falas" (leitura) das parlendas. Perceber que o smartphone transformou-se num recurso didático de fácil utilização e que traz o fortalecimento do estímulo, da criação, deixa a aula mais leve, faz com que os alunos se concentrem mais. (Professora Nany).

Durante a formação, participamos de uma caça ao tesouro, usando $Q R$ Code, que eu achei muito interessante e fiz com os alunos de $6^{\circ}$ ano. Essa turma ainda não conhecia o $Q R$ Code, portanto, iniciamos explorando esses códigos e conhecendo os recursos. A sala tem 30 alunos e foi dividida em 6 grupo, cada um com 5 participantes. Para fazer a divisão dos grupos, também usei os mesmos códigos, com números de 1 a 6 . Cada equipe tinha que ter pelo menos 1 celular com leitor de $Q R$ Code. Apenas um aluno já tinha esse leitor no seu celular, os outros baixamos na hora (1 por equipe). Coloquei as pistas em diversos pontos estratégicos. Em cada pista tinha um problema a ser resolvido e a resposta era o número da pista seguinte. (Profa. Paola).

Utilizei duas estratégias usadas nas aulas, o aplicativo Your Shot que seleciona grupos e escolhe por meio de sorteio eletrônico um aluno para responder uma questão. A tarefa foi utilizada com 
a professora de Português do $6^{\circ}$ Ano. Também repassei ao professor de educação física que tem utilizado para dividir os alunos em grupo. (Prof. Pereira).

As falas dos professores referem-se ao momento em que desenvolveram, em suas salas de aula, práticas que envolveram os multiletramentos, organizadas sob a forma de sequências didáticas e socializadas no último encontro presencial.

Durante a socialização da produção, e na avaliação do projeto, refletimos a respeito do comprometimento/engajamento dos participantes no decorrer de todo o processo formativo, tanto nos encontros presenciais quanto no ambiente Moodle: “[...] as temáticas abordadas eram ótimas, aprendi muito e só tenho a agradecer a todas vocês que me proporcionaram esse momento rico de aprendizagens". (Profa. Marta).

Ressaltamos que a realização desse projeto de extensão configurou-se como uma ação formativa para o professor em serviço, mas também para seus alunos, pois o movimento de levar à sala de aula as experiências vivenciadas no curso propiciou ao professor pensar nas necessidades de seus alunos, tornando a aprendizagem mais significativa para esses sujeitos.

\section{Reflexões finais sobre um processo de pesquisa em constante devir}

As pesquisas a respeito de letramentos, multiletramentos, prática pedagógica e formação de professores, realizadas até 2018, levam-nos a compreender que práticas de leitura e de escrita, tanto em meios impressos quanto digital, configuram-se como potencializadores pedagógicos para ensino e aprendizagem mais significativos. Também, contribuem para a promoção de práticas educativas críticas, reflexivas e plurais, que desenvolvam nos alunos habilidades cognitivas que apontem para a produção coletiva de saberes.

Nessa perspectiva, os estudos realizados pelo grupo de pesquisa, no âmbito da pósgraduação stricto sensu, apresentam-se como forma de promover, no espaço escolar, a construção de uma pedagogia culturalmente sensível que leve em conta a diversidade de práticas sociais de leitura e de escrita em diversos meios textuais. As pesquisas que desenvolvemos, no âmbito dos programas de pós-graduação stricto sensu, nos apontam um caminho a trilhar, rumo à pesquisa-formação, que tem traço mediador para a construção de uma prática pedagógica que considere todas as possiblidades de letramentos no repertório humano. Na época atual, são necessárias aos alunos aprendizagens diferenciadas em relação aos modos de interagir com o texto - agora, multimodal e multissemiótico -, através de ações multiletradas.

Essas experiências de pesquisa colaborativa formativa têm nos permitido problematizar a formação docente, a partir de uma parceria entre universidade e escola, criando espaço para que os professores possam compreender suas práticas docentes de forma articulada à prática social, de modo a gerar mudanças na cultura escolar.

Entendemos que o trabalho a partir dos multiletramentos poderá dar sentido e reestruturar a função social da escola, que não é mais a de formar corpos dóceis e úteis, mas sujeitos - professores e alunos - que, diante do colapso de um modelo de reprodução 
que se baseava em um letramento único, possam transitar em diversas agências da cultura letrada, oportunizadas pelas mídias impressas ou digitais.

\section{Referências}

ANDRÉ, Marli. Pesquisa, formação e prática docente. In: ANDRÉ, Marli (org.). 0 papel da pesquisa na formação e prática dos professores. Campinas: Papirus, 2002. p. 55-70.

BAKHTIN, Mikhail M. (Valentin Nikoláievitch Volochínov). Marxismo e filosofia de linguagem. São Paulo: Hucitec, 2004.

BAZERMAN, Charles. Escrita, gênero e interação social. São Paulo: Cortez, 2007.

BORBA; Marília dos Santos; ARAGÃ0, Rodrigo. Multiletramentos: novos desafios e práticas de linguagem na formação de professores de inglês. Polifonia, Cuiabá, v. 19, n. 25, p. 223-240, jan./jul. 2012. Disponível em: https://periodicoscientificos.ufmt.br/ojs/index.php/polifonia/article/view/576. Acesso em: 12 fev. 2021.

BUZATO, Marcelo. Novos letramentos e apropriação tecnológica: conciliando heterogeneidade, cidadania e inovação em rede. In: RIBEIRO, Ana Elisa et al. (org.). Linguagem, tecnologia e educação. São Paulo: Peirópolis, 2010. p. 41-53.

COPE, Bill; KALANTZIS, Mary. Multiliteracies: the beginnings of an idea. In: COPE, Bill; KALANTZIS, Mary (org.). Multiliteracies: literacy learning and the design of social futures. New York: Routledge, 2000. p. 3-8.

ERICKSON, Frederick. Qualitative methods in research on teaching. In: WITTROCKK, Merlin (ed.). Handbook of research on teaching. 3 ed. New York: MacMillan, 1986. Disponível em: https://pdfs.semanticscholar. org/c74e/735826d50018235b98dd4723a9fad28b3956.pdf. Aceso em: 06 ago. 2018. 119-161.

FERREIRA, Helena Maria. A estratégia da ressemiotização e o ensino de leitura: contribuições para a formação de professores. Revista Devir Educação, Lavras, v. 2, n. 1, p. 37-54, jan./jun. 2018. Disponível em: http://devireducacao.ded.ufla.br/index.php/DEVIR/article/download/57/56/. Acesso em: 06 ago. 2018.

GÓMEZ. Angel Pérez. As funções sociais da escola: da reprodução à reconstrução crítica do conhecimento e da experiência. In: SACRISTÁN, Gimeno. Compreender e transformar o ensino. 4 ed. Porto Alegre: Artmed, 1998. p. 13-26.

HYMES, Dell. Sobre competência comunicativa. Revista Desempenho, Brasília, DF, v. 10, n. 1, p. 74-104, jun. 2009. Disponível em: www.revistadesempenho.org.br. Acesso em 02 jan. 2014.

IBIAPINA, Ivana Maria Lopes de Melo. Pesquisa colaborativa: investigação, formação e produção de conhecimentos. Brasília, DF: Liber Livros, 2008.

IBIAPIANA, Ivana Maria Lopes de Melo; RIBEIRO, Marcia Maria Gurgel; FERREIRA, Maria Salonilde (org.). Pesquisa em educação: múltiplos olhares. Brasília, DF: Líder Livro, 2007. 
KLEIMAN, Ângela. Preciso "ensinar" o letramento? Não basta ensinar a escrever? Brasília, DF: Ministério da Educação, 2005.

KRESS, Gunther; LEITE-GARCIA, Regina; VAN LEEUWEN, Theo. Semiótica discursiva. In: VAN DIJK, Teun. A. El discurso como estrutura y processo. Barcelona: Gedisa, 2000. p. 373-416.

LÉVY, Pierre. Cibercultura. Trad. Carlos Irineu da Costa. Rio de Janeiro: 34, 1999.

NLG. The New London Group. A pedagogy of multiliteracies: designing social futures. In: COPE, Bil; KALANTZIS, Mary. Multiliteracies: literacy and the design soial futures. London: Routledge, 2000. p. 9-37.

PIMENTA, Selma Garrido; GHEDIN, Evandro (org.). Professor reflexivo no Brasil: gênese e crítica de um conceito. São Paulo: Cortez, 2002.

PRETTO, Nelson de Luca. Uma escola sem/com futuro: educação e multimídia. 8. ed. rev. e atual. Salvador: UFBA, 2013.

R0J0, Roxane Helena R. Cenários futuros para as escolas. In: Fundação Telefônica (org.). Educação no Século XXI. São Paulo: Fundação Telefônica, 2013. p. 19-22. Disponível em: http://fundacaotelefonica. org.br/wp-content/uploads/2013/03/caderno3_multiletramentos.pdf. Acesso em: 21 fev. 2021.

R0J0, Roxane Helena R. Diversidade cultural e de linguagens na escola. In: R0J0, Roxane; MOURA, Eduardo (org.). Multiletramentos na escola. São Paulo: Parábola, 2012. p. 11-31.

ROJO, Roxane Helena R. Letramentos múltiplos, escola e inclusão social. São Paulo: Parabola, 2009.

ROJ0, Roxane Helena R.; BARBOSA, Jaqueline. Hipermodernidade, multiletramentos e gêneros discursivos. São Paulo: Parábola, 2015.

SÁNCHEZ VÁZQUEZ, Adolfo. Filosofia da práxis. 2. ed. Buenas Aires: Consejo Latinoamericano de Ciencias Sociales Clacso: São Paulo: Expressão Popular, 2011.

SEVERINO, Antônio Joaquim. Metodologia do trabalho científico. São Paulo: Cortez, 2002.

SOARES, Magda. Letramento: um tema em três gêneros. Belo Horizonte: Autêntica, 2004.

STREET, Brian. Eventos de letramento e práticas de letramento: teoria e prática aos novos estudos de letramento. In: MAGALHÃES, Izabel (org.). Discursos e práticas de letramento: pesquisa etnográfica e formação de professores. Campinas: Mercado de Letras, 2012. p. 69-92.

STREET, Brian. Letramentos sociais: abordagens críticas do letramento no desenvolvimento, na etnografia e na educação. Tradução de Marcos Bagno. São Paulo: Parábola, 2014.

TFOUNI, Leda Verdiani. Letramento e alfabetização. São Paulo: Cortez, 2010. 
Recebido em: 10.03.2019

Revisado em: 11.09.2019

Aprovado em: 12.11.2019

Obdália Santana Ferraz Silva é professora adjunta do Departamento de Educação da Universidade do Estado da Bahia (UNEB). Docente dos Programas de Pós-Graduação Educação e Diversidade (MPED/UNEB) e Educação e Contemporaneidade (PPGEDUC/UNEB).

Úrsula Cunha Anecleto é professora adjunta do Departamento de Educação da Universidade Estadual de Feira de Santana (UEFS). Docente dos Programas de Pós-Graduação em Estudos Linguísticos (PPGEL/UEFS) e Educação (PPGE/UEFS).

Sirlaine Pereira Nascimento dos Santos é coordenadora pedagógica na Secretaria Municipal de Educação da Prefeitura Municipal de Salvador. Doutoranda e mestre em educação e contemporaneidade pelo Programa de Pós-Graduação em Educação e Contemporaneidade da Universidade do Estado da Bahia (PPGEDUC/UNEB). 